\title{
A CASE OF ORO-PHARYNGEAL TERATOMA (EPIGNATHUS) IN A NEONATE WITH DIFFICULT AIRWAY: A CASE REPORT
}

M. R. Karthikeyan1, N. Krishnan²

\section{HOW TO CITE THIS ARTICLE:}

M. R. Karthikeyan, N. Krishnan. "A Case of ORO-Pharyngeal Teratoma (Epignathus) in a Neonate with difficult Airway: A Case Report". Journal of Evolution of Medical and Dental Sciences 2015; Vol. 4, Issue 84, October 19; Page: 14745-14747, DOI: $10.14260 /$ jemds/2015/2098

ABSTRACT: Epignathus is a midline oropharyngeal teratoma, usually presents with severe respiratory obstruction. Securing airway in these neonates is a real nightmare for a paediatric anesthesiologist. We report a case of Epignathic teratoma in a 2day old neonate with severe stridor. Awake tracheal intubation was performed because of non-availability of smaller fibre optic bronchoscope.

KEYWORDS: Epignathus, Difficult airway, Neonate, Awake tracheal intubation.

INTRODUCTION: Epignathus is an extremely rare congenital oropharyngeal teratoma that commonly arises from the palate leading to a high mortality secondary to airway obstruction in the neonatal period. Its incidence ranges from 1:35, 000 to 2, 00, 000 live births and has a female predominance. Neonates with oropharyngeal teratomas (Epignathus) can present considerable challenges in airway managements to anesthesiologists.

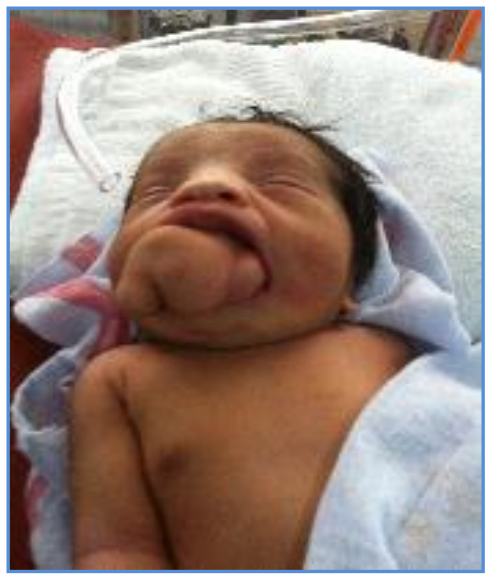

Fig. 1

CASE REPORT: A 2 day old, term, female baby weighing 3kg, born by normal vaginal delivery was admitted in our surgical newborn unit with a huge mass protruding from the mouth with respiratory distress (Figure 1). The anesthesiologist was called for airway management.

On clinical examination, the neonate was pink in colour, with good cry, HR of 154/min and maintaining SpO2 of $90 \%$ with 02.The respiratory rate was $60 / \mathrm{min}$ and there were severe intercostal retractions.

The mass was a midline teratoma.(1) which was bony non pedunculated arising from the oral cavity, completely attached to hard palate above and to the lower jaw below, with very minimal space on the left side and no space on the right side of the protruding mass. The right nostril was found to be obliterated and the left nostril allowed $8 \mathrm{Fr}$ feeding tube. 


\section{CASE REPORT}

\section{Options to secure airway in this neonate were:}

a) Fiberoptic bronchoscopy guided intubation.(2)

b) Emergency Tracheostomy

c) Awake trial laryngoscopy and intubation.(3)

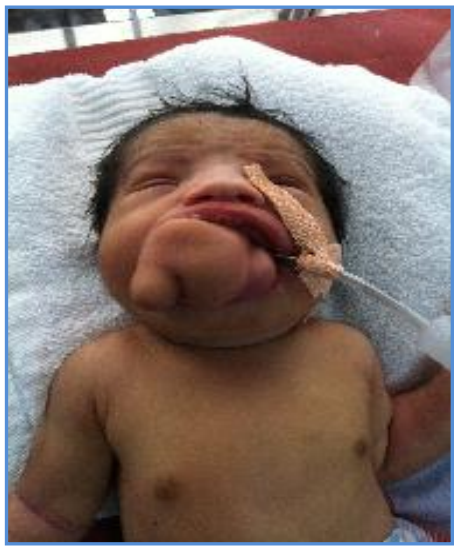

Fig. 2

Since we did not have the neonatal (2.2) fibre optic bronchoscope we were left with the options of emergency tracheostomy and awake trial laryngoscopy.(3) Because of the anticipated difficulty in maintaining anaesthesia for this particular neonate with mass protruding from the mouth and fear of losing the airway during tracheostomy, we opted for awake trial laryngoscopy and intubation. The difficult airway cart with all the emergency drugs were kept ready and the ENT surgeons were present as a standby. Inj. Atropine $0.1 \mathrm{mg}$ I.V. was given prior to laryngoscopy. Since there was very minimal working space a 1 size Miller blade was used instead of Macintosh blade. After retracting the left cheek laterally with the Miller blade, the mass was found to occupy the entire oral cavity leaving behind space just enough to pass the endotracheal tube. With little external laryngeal pressure, the epiglottis and posterior half of the glottis could be visualised. A 3mm ID un-cuffed endotracheal tube with stylet was negotiated through the available space into the glottic opening. After confirmation of correct placement, the endotracheal tube was fixed on the left side of the oral cavity (Figure 2). Immediately after securing the airway, the baby became very comfortable and maintained $99 \%$ saturation even without oxygen.

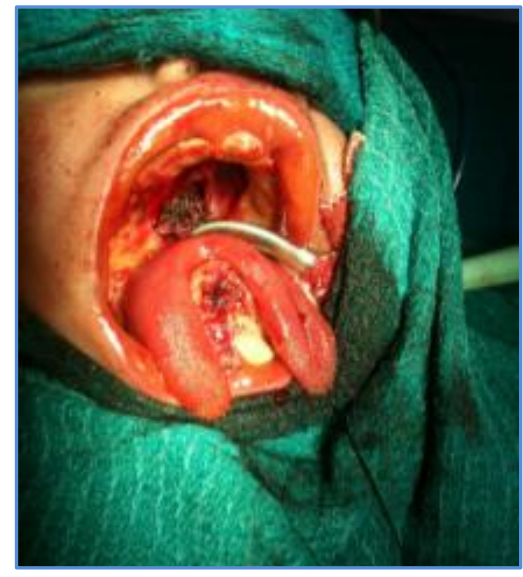

Fig. 3 
After thorough evaluation, the neonate was posted for surgery the next day which was uneventful (Figure 3). The baby was extubated after 48hrs of elective ventilation.

DISCUSSION: Careful preoperative assessment of the airway is always more important and sufficient preparation and careful intubation are mandatory to keep the airway patent.

FOB guided intubation.(2) is the gold standard approach to manage any difficult airway. Despite the availability of several techniques and devices for management of difficult airway, awake intubation.(2) under direct laryngoscopy particularly in the neonates with these types of problems is a safe and alternate approach in experienced hands.

\section{REFERENCES:}

1. Izadi K Smith M Askari Metal. A patient with an epignathus: Management of a large oropharyngeal teratoma in a newborn. J Cranifac Surg 2003: 14, 468-472.

2. Miyoshi:E, Kitamursa S, Kinouchi $\mathrm{K}$ et al. Anaesthetic management for newborn pharyngeal teratoma. Masui: 1999, 48.884-887.

3. Jin - Xi -gLiu, Yu Sun Hong Jiang, Ye-Sen Zhu. Left para glossal approach for a newborn with midline teratoma Paediatric anaesthesia, 2010: 20.279-293.

\section{AUTHORS:}

1. M. R. Karthikeyan

2. N. Krishnan

\section{PARTICULARS OF CONTRIBUTORS:}

1. Senior Assistant Professor, Department of Anaesthesiology, Institute of Child Health and Hospital for Children, Madras Medical College, Chennai, Tamilnadu.

2. Professor, Department of Anaesthesiology, Institute of Child Health and Hospital for Children, Madras Medical College, Chennai, Tamilnadu.

\section{NAME ADDRESS EMAIL ID OF THE} CORRESPONDING AUTHOR:

Dr. M. R. Karthikeyan,

Flat C-8, Block 1, Jain Amrit Kalash Apartments, 159, Strahans Road,

Pattalam, Chennai- 12.

E-mail: drkarthimr2000@gmail.com

Date of Submission: 24/09/2015. Date of Peer Review: 25/09/2015. Date of Acceptance: 08/10/2015. Date of Publishing: 19/10/2015.

\section{COMPETING INTERESTS: None}

